\title{
PENERAPAN STRATEGI MASTERY LEARNING UNTUK MENINGKATKAN HASIL BELAJAR MAHASISWA PADA MATA KULIAH FISIKA DASAR II
}

\author{
Azizahwati $^{1)}$, Sugoro Bhakti Sutono ${ }^{2)}$, Salman Alfarisi ${ }^{3)}$ \\ ${ }^{1)}$ FKIP Universtas Riau \\ ${ }^{2,3)}$ Sekolah Tinggi Teknologi Pelalawan \\ e-mail: azizahwati@lecturer.unri.ac.id \\ sb.sutono@st2p.ac.id \\ salmanalfarisi456@gmail.com
}

\begin{abstract}
Abstrak
Penelitian ini bertujuan untuk mendeskripsikan hasil belajar fisika dasar II mahasiswa Teknik Industri Sekolah Tinggi Teknologi Pelalawan pada materi kelistrikan. Subjek penelitiannya adalah mahasiswa semester 2 Teknik Industri Sekolah Tinggi teknologi Pelalawan. Instrumen yang digunakan untuk pengumpulan data adalah tes hasil belajar yang diberikan sesudah penerapan strategi mastery learning. Data dianalisis dengan menggunakan teknik analisis deskriptif yang meliputi tingkat penguasaan mahasiswa. Hasil analisis data menunjukkan hasil belajar mahasiswa dikategorikan cukup. Penerapan strategi mastery learning dapat meningkatkan hasil belajar fisika mahasiswa pada materi kelistrikan.
\end{abstract}

Kata kunci: hasil belajar, Mastery learning

\begin{abstract}
This research aims to describe the learning outcomes of basic physics learning II students Industrial Engineering of Pelalawan Institute of Technologyon the concept of electricity. The subject of this research is the second semester students of Industrial Engineering of Pelalawan Institute of Technology. The instrument used for data collection is the learning outcomes test given after the application of mastery learning strategy. Data were analyzed using descriptive analysis technique covering the students' learning achievement. The results of data analysis showed student learning outcomes categorized average. Application of strategy Mastery learning can improve student's basic physics learning outcomes on electrical materials.
\end{abstract}

Keywords: learning outcomes, Mastery Learning 


\section{Pendahuluan}

Hasil belajar merupakan suatu penilaian yang dilakukan untuk melihat kemajuan peserta didik terhadap apa yang telah ia pelajari yang dijadikan pedoman dalam menentukan kemampuan siswa (Hamzah 2010). Tingkah laku yang mengalami perubahan karena belajar menyangkut berbagai aspek kepribadian, baik fisik maupun psikis, seperti: perubahan dalam pengertian pemecahan suatu masalah, keterampilan kecakapan, kebiasaan, ataupun sikap. Belajar merupakan sesuatu perubahan yang diperoleh seseorang melalui latihan atau pengalaman (Djamarah, 2002). Tingkah laku yang mengalami perubahan karena belajar menyangkut berbagai aspek kepribadian, baik fisik maupun psikis, seperti: perubahan dalam pengertian pemecahan suatu masalah/berfikir, keterampilan kecakapan, kebiasaan, ataupun sikap (Purwanto, 2007).

Tabel 1. Tahapan belajar pada Strategi Mastery Learning

\begin{tabular}{|c|c|c|c|}
\hline No & $\begin{array}{c}\text { Tahapan } \\
\text { Belajar }\end{array}$ & Kegiatan Guru & Kegiatan Peserta Didik \\
\hline \multirow[t]{4}{*}{1.} & Orientasi & Menetapkan isi pembelajaran & $\begin{array}{llll}\begin{array}{l}\text { Bertanya tentang isi pem- } \\
\text { belajaran }\end{array} & & & \\
\end{array}$ \\
\hline & & $\begin{array}{l}\text { Meninjau ulang pembelajaran } \\
\text { sebelumnya }\end{array}$ & $\begin{array}{l}\text { Mengingat kembali pem- } \\
\text { belajaran sebelumnya }\end{array}$ \\
\hline & & Menetapkan tujaun pembelajaran & $\begin{array}{l}\text { Memahami tujuan pembelajaran } \\
\text { yang harus dicapai }\end{array}$ \\
\hline & & $\begin{array}{l}\text { Menetapkan langkah-langkah } \\
\text { pembelajaran }\end{array}$ & $\begin{array}{l}\text { Bertanya/mendiskusikan } \\
\text { langkah-langkah pembelajaran. }\end{array}$ \\
\hline \multirow[t]{2}{*}{2.} & Penyajian & $\begin{array}{l}\text { Menjelaskan/memeragakan } \\
\text { konsep/keterampilan baru }\end{array}$ & Memperhatikan, bertanya \\
\hline & & $\begin{array}{l}\text { Menggunakan media visual/ } \\
\text { audiovisual untuk menjelaskan }\end{array}$ & Mendiskusikan, bertanya \\
\hline \multirow[t]{3}{*}{3.} & $\begin{array}{l}\text { Latihan } \\
\text { terstruktur }\end{array}$ & $\begin{array}{l}\text { Guru memberikan contoh } \\
\text { langkah-langkah penting } \\
\text { menyelesaikan tugas/soal }\end{array}$ & $\begin{array}{l}\text { Memperhatikan, } \text { bertanya, } \\
\text { mendiskusikan. }\end{array}$ \\
\hline & & $\begin{array}{l}\text { Guru memberikan pertanyaan } \\
\text { pada siswa. }\end{array}$ & Menjawab pertanyaan guru \\
\hline & & $\begin{array}{l}\text { Guru memberikan umpan balik } \\
\text { (yang bersifat korektif) atas } \\
\text { kesalahan siswa dan mendorong- } \\
\text { nya untuk menjawab dengan } \\
\text { benar setiap tugas yang diberikan. }\end{array}$ & $\begin{array}{l}\text { Mencermati umpan balik dari } \\
\text { guru, jika ada hal yang belum } \\
\text { jelas bertanya lagi pada guru. }\end{array}$ \\
\hline \multirow[t]{2}{*}{4.} & $\begin{array}{l}\text { Latihan } \\
\text { terbimbing }\end{array}$ & Guru memberikan tugas & $\begin{array}{lcc}\text { Siswa mengerjakan } & \text { tugas } \\
\text { dengan } & \text { semi bimbingan. }\end{array}$ \\
\hline & & $\begin{array}{l}\text { Guru mengawasi semua siswa } \\
\text { secara merata. }\end{array}$ & $\begin{array}{l}\text { Siswa mengerjakan tugas } \\
\text { dengan semi bimbingan. }\end{array}$ \\
\hline
\end{tabular}




\begin{tabular}{|c|c|c|c|}
\hline No & $\begin{array}{l}\text { Tahapan } \\
\text { Belajar }\end{array}$ & Kegiatan Guru & Kegiatan Peserta Didik \\
\hline & & $\begin{array}{l}\text { Guru memberikan umpan balik, } \\
\text { memuji dan sebagainya. }\end{array}$ & $\begin{array}{l}\text { Mencermati umpan balik dari } \\
\text { guru, jika ada hal yang belum } \\
\text { jelas bertanya lagi pada guru. }\end{array}$ \\
\hline \multirow[t]{3}{*}{5.} & $\begin{array}{l}\text { Latihan } \\
\text { mandiri }\end{array}$ & Guru member tugas mandiri & $\begin{array}{l}\text { Siswa mengerjakan tugas di } \\
\text { kelas/di rumah secara mandiri. }\end{array}$ \\
\hline & & $\begin{array}{l}\text { Guru memeriksa dan jika perlu } \\
\text { memberikan umpan balik atas } \\
\text { hasil kerja siswa. }\end{array}$ & $\begin{array}{l}\text { Mencermati umpan balik dari } \\
\text { guru, jika ada hal yang belum } \\
\text { jelas bertanya lagi pada guru. }\end{array}$ \\
\hline & & $\begin{array}{l}\text { Guru memberikan beberapa tugas } \\
\text { mandiri sebagai alat untuk } \\
\text { meningkatkan retensi siswa. }\end{array}$ & $\begin{array}{l}\text { Mengerjakan tugas yang } \\
\text { diberikan secara mandiri. }\end{array}$ \\
\hline
\end{tabular}

Mata kuliah fisika dasar II merupakan salah satu mata kuliah wajib bagi mahasiswa Teknik Industri di ST2P (Sekolah Tinggi Teknologi Pelalawan). Salah satu materi pada mata kuliah ini yang dianggap sulit oleh mahasiswa adalah materi kelistrikan (Smith \& Kampen,2001; Kock et al., 2014). Pemberian latihan yang terbimbing masih kurang dilakukan dalam perkuliahan, sehingga menyebabkan rendahnya hasil belajar pada materi ini.

Melihat kondisi tersebut, maka perlu dilakukan suatu perbaikan. Perbaikan yang dapat dilakukan adalah dengan menerapkan strategi pembelajaran. Tujuan utama dari strategi belajar menurut Wiensteind \& Meyer dalam Djamarah (2002) adalah mengajarkan siswa untuk belajar atas kemauan dan kemampuan diri sendiri. Siswa yang dapat belajar atas kemauan dan kemampuan diri sendiri dengan strategi belajar tertentu dikatakan sebagai pembelajar mandiri.

Menurut Arends (dalam Agus Suprijono, 2013), terdapat 4 hal penting yang harus dilakukan pelajar agar menjadi pembelajar yang mandiri yaitu; (1) Secara cermat mendiagnosis suatu situasi pembelajaran tertentu, (2) Memilih strategi belajar tertentu untuk menyelesaikan masalah belajar tertentu yang dihadapi, (3) Memonitor keefektifan strategi tersebut, (4) Cukup termotivasi untuk terlibat dalam situasi belajar tersebut sampai masalah tersebut terselesaikan.

Salah satu cara untuk meningkatkan hasil belajar belajar pada materi ini adalah dengan menerapkan stretegi mastery learning (pembelajaran tuntas) pada mahasiswa Jurusan Teknik Industri ST2P. Menurut Wena (2009), mastery learning merupakan suatu cara yang menarik dan ringkas untuk meningkatkan unjuk kerja siswa ke tingkat pencapaian suatu pokok bahasan yang lebih memuaskan. Strategi pembelajaran ini terdiri atas lima tahap, yaitu (a) orientasi (orientation) (b) penyajian (presentation), (c) latihan terstruktur (structured practice), (d) latihan terbimbing (guided practice), dan (e) latihan mandiri (independent practice). Menurut Wena (2009), secara operasional kegiatan guru dan peserta didik selama proses pembelajaran dapat dijabarkan seperti pada Tabel 1.

Menurut Abu Ahmadi (2005) ada beberapa ciri mastery learning yaitu :

1. Peserta didik dapat belajar dengan baik sesuai dengan harapan dalam kondisi pengajaran yang tepat.

2. Bakat seorang peserta didik dalam bidang pengajaran dapat diramalkan, baik tingkatannya maupun waktu yang dibutuhkan untuk mempelajari bahan tersebut. Bakat berfungsi sebagai indeks tingkatan belajar peserta didik dan sebagai suatu ukuran satuan waktu.

3. Tingkat hasil belajar bergantung pada waktu yang digunakan secara nyata oleh peserta didik untuk mempelajari sesuatu dibandingkan dengan waktu yang dibutuhkan untuk mempelajarinya.

4. Setiap peserta didik memperoleh kesempatan belajar yang berdiferensiasi 
dan kualitas pengajaran yang berdiferensiasi pula.

Metode pembelajaran yang sangat ditekankan dalam mastery learning adalah pembelajaran individual, pembelajaran dengan teman atau sejawat (peer instruction) dan bekerja dalam kelompok kecil. Berbagai jenis metode pembelajaran harus digunakan untuk kelas atau kelompok. Strategi mastery learning sangat mengandalkan pada pendekatan tutorial dengan kelompok kecil, tutorial orang perorang, pembelajaran terprogram, bukubuku ajar, permainan, peralatan dan komputer. Menurut Sukmadiata (2005), melalui setrategi mastery learning proses belajar mengajar akan lebih efektif dan efisien sehingga tujuan instruksional yang diinginkan dapat tercapai.

\section{Bahan dan Metode}

Penelitian ini dilaksanakan pada semester genap 2015/2016. Subjek penelitiannya adalah mahasiswa semester 2 Teknik Industri Sekolah Tinggi Teknologi Pelalawan. Rancangan penelitian yang digunakan adalah The one shot case study. Instrumen yang digunakan untuk pengumpulan data adalah tes hasil belajar yang diberikan sesudah penerapan strategi mastery learning. Data yang diperoleh dianalisis dengan menggunakan teknik anlisis deskriptif untuk menentukan tingkat penguasaan mahasiswa.

Tabel 2. Tingkat penguasaan mahasiswa

\begin{tabular}{|c|c|c|}
\hline $\begin{array}{c}\text { Tingkat } \\
\text { Penguasaan }\end{array}$ & Kriteria & Keterangan \\
\hline$\geq 80-100$ & Sangat Baik & $\begin{array}{l}\text { Menguasai hampir } \\
\text { semua konsep }\end{array}$ \\
\hline$\geq 70-<80$ & Baik & $\begin{array}{l}\text { Menguasai sebagian } \\
\text { besar konsep }\end{array}$ \\
\hline$\geq 60-<70$ & Cukup & $\begin{array}{l}\text { Menguasai separoh } \\
\text { konsep }\end{array}$ \\
\hline$\geq 50-<60$ & Kurang & $\begin{array}{l}\text { Menguasai sebagian } \\
\text { kecil konsep }\end{array}$ \\
\hline$<50$ & Kurang Sekali & $\begin{array}{l}\text { Hampir tidak } \\
\text { menguasai konsep }\end{array}$ \\
\hline
\end{tabular}

Sumber: Depdiknas (2006).

\section{Hasil dan Pembahasan}

Penelitian yang telah dilakukan memberikan gambaran hasil belajar untuk materi kelistrikan melalui penerapan strategi pembelajaran tuntas.

Berdasarkan Tabel 2, mahasiswa yang mengambil mata kuliah ini menguasai sebagian besar konsep kelistrikan. Hal ini mengindikasikan bahwa; (1) mahasiswa termotivasi mengikuti perkuliahan, (2) mahasiswa sebagian besar memahami materi kelistrikan, (3) Lembar latihan terbimbing dan latihan mandiri membuat mahasiswa lebih terarah untuk menguasai konsep, (4) melalui pemberian latihan terbimbing dan latihan mandiri sangat membantu mahasiswa dalam menguasai konsep kelistrikan. Depdiknas (2008) menjelaskan bahwa harapan dari proses pembelajaran dengan strategi mastery learning adalah untuk mempertinggi rata-rata prestasi peserta didik dalam belajar.

Mahasiswa memiliki penguasaan yang sangat baik dalam konsep kelistrikan sebesar $30,76 \%$. Hal ini menunjukkan bahwa terjadi peningkatan tingkat penguasaan mahasiswa pada konsep kelistrikan. Menurut Kunandar (2007) mastery learning adalah suatu system belajar yang menginginkan sebagian besar peserta didik dapat menguasai tujuan pembelajaran secara tuntas. Tingkat penguasaan mahasiswa dengan kriteria sangat baik dalam penelitian ini, disebabkan karena mahasiswa dituntut untuk dapat menyelesaikan tugas yang diberikan setiap pembelajaran. Mahasiswa secara berkelompok mengerjakan tugas sehingga memperoleh hasil yang maksimal. Mulyasa (2004) mengatakan bahwa belajar tuntas adalah suatu strategi pengajaran yang diindividualisasikan dengan menggunakan pendekatan kelompok. Partisipasi yang muncul di dalam kelompok pada saat pembelajaran dimaksudkan sebagai keterlibatan mental dan emosi serta fisik setiap anggota sehingga mampu mencapai tujuan yang diinginkan dan juga setiap anggota dalam kelompok bertanggung jawab atas keterlibatan mereka di dalam kelompok (Suryo Subroto, 2002). Strategi ini memungkin mahasiswa belajar lebih aktif, sehingga memberikan kesempatan untuk mengembangkan diri. Latihan terbimbing dan latihan mandiri yang diberikan membantu mahasiswa memahami selangkah demi selangkah konsep yang akan 
Tabel 2. Tingkat penguasaan mahasiswa pada materi pokok fisika dasar

\begin{tabular}{lll}
\hline Tingkat Penguasaan & Persentase (\%) & Kriteria \\
\hline$\geq 80-100$ & 30,76 & Sangat Baik \\
$\geq 70-<80$ & 7,70 & Baik \\
$\geq 60-<70$ & 38,46 & Cukup \\
$\geq 50-<60$ & 23,08 & Kurang \\
$<50$ & 0 & Kurang Sekali \\
\hline Daya serap rata-rata & & 67,68 \\
\hline Kategori & & Cukup
\end{tabular}

diperoleh sehingga mahasiswa menjadi lebih memahami konsep kelistrikan. Penguasan konsep kelistrikan yang diperoleh dengan menggunakan strategi mastery learning ini sejalan dengan hasil penelitian yang dilakukan oleh Ajogbeje (2012), Majid \& Zahra (2010), Olufunmilayo (2010), Telimoye \& Obaitan (2015).

Walaupun demikian terdapat sebanyak $23,08 \%$ mahasiswa yang masih berada pada tingkat penguasaan yang kurang. Hal ini disebabkan oleh masih adanya mahasiswa yang masih bingung dengan pembacaan rangkaian (Kock et al, 2014) dan membedakan besaran-besaran listrik (Rosenthal \& Henderson, 2006).

Rata-rata tingkat penguasaan mahasiswa adalah $67,68 \%$. Penguasaan yang dimiliki mahasiswa, karena mahasiswa belajar lebih aktif dalam pembelajaran. Secara keseluruhan daya tahan konsep (retensi) yang dimiliki mahasiswa melalui penerapan strategi mastery learning menjadi lebih baik. Mahasiswa yang tergolong lambat menguasai konsep secara tuntas dapat belajar hampir sama dengan mahasiswa yang mempunyai kemampuan lebih tinggi (Made Alit Mariana, 2003). Strategi ini juga memberi kesempatan kepada mahasiswa untuk mengembangkan diri. Selain itu melalui starategi mastery learning dosen dan mahasiswa diminta bekerja sama secara partisipatif dan persuasif, baik dalam proses belajar maupun dalam proses bimbingan. Strategi mastery learning berorientasi kepada peningkatan produktivitas hasil belajar. Secara umum keuntungan penggunaan strategi pembelajaran ini adalah: mahasiswa dapat menguasai isi pembelajaran, motivasi belajar mahasiswa meningkat, mampu meningkatkan kemampuan pemecahan masalah dan meningkatkan kepercayaan diri mahasiswa (Olufunmilayo, 2010). Kesemua ini mengakibatkan peningkatan hasil belajar mahasiswa pada konsep kelistrikan.

\section{Kesimpulan dan Saran}

Berdasarkan hasil penelitian yang telah dicapai, maka dapat disimpulkan bahwa daya serap rata-rata mahasiswa melalui penerapan strategi mastery learning pada konsep kelistrikan adalah 67,68\% dengan kategori cukup yang menunjukkan bahwa mahasiswa sebagian besar telah menguasai konsep. Melalui penerapan strategi mastery learning dapat meningkatkan hasil belajar mahasiswa Teknik Industri Sekolah Tinggi Teknologi Pelalawan dalam materi kelistrikan pada semester 2 tahun akademik 2015/2016. Masih terdapat kekurangan dalam implementasi pembelajaran. Untuk itu diperlukan upaya yang lebih maksimal agar dapat meningkatkan daya serap mahasiswa. Untuk mengatasi tingkat kesulitan mahasiswa, maka penelitian selanjutnya perlu diberikan pengetahuan awal yang baik terhadap konsep dan media pembelajaran yang optimal, sehingga hasil yang didapat bisa lebih baik.

\section{Daftar Pustaka}

Abu Ahmadi, 2005. Strategi Belajar Mengajar. Pustaka Setia, Bandung. 
Agus Suprijono, 2013. Cooperative Learning Teori dan Aplikasi PAIKEM. Pustaka Pelajar, Yogyakarta.

Ajogbeje, O. J., 2012. Path-analytic model and the effect of some teaching strategies on variables affecting achievement in junior secondary school mathematics in Ondo State. Unpublished Ph.D. Thesis, Ekiti State University, Ado - Ekiti, Nigeria.

Depdiknas, 2006. Panduanumum Pengembangan Sistem Assesmen Berbasis Kompetensi (Buku I). Direktorat Jendral pendidikan Tinggi, Jakarta.

Depdiknas, 2008. Panduan Penyelenggaraan Pembelajaran Tuntas (MasteryLearning). Depdiknas, Jakarta.

Djamarah, 2002. Strategi Belajar Mengajar. Rineka Cipta, Jakarta.

Hamzah, B., 2010. Perencanaan Pembelajaran. Bumi Aksara, Jakarta.

Kock, Z., Taconis, R., Bolhuis, S \& Graveimejer, K., 2014. Creating A Culture Of Inquiry In The Classroom While Fostering An Understanding Of Theoretical Concepts In Direct Current Electric Circuits: A Balanced Approach.International Journal of Science and Mathematics Education (IJMSE), 13 (1), 45-69.

Kunandar, 2007. Guru Profesional. Rajawali Pres, Jakarta.

Made Alit Mariana, 2003. Pembelajaran Remedial.Dirjen Dikdsasmen, Jakarta.

Majid,E.D., \& Zahra, S. K., 2010. Effect of mastery learning method on performance and attitude of weak students in chemistry. Elsevier Ltd. Iran.

Mulyana, 2004. Implementasi Kurikulum 2004 Pedoman Belajar KBK. Rosdakarya, Bandung.

Olufunmilayo, I. O., 2010. Enhanced mastery learning strategy on achievement and self concept in senior secondary school chemistry. Humanity and social sciences journal, 5 (1), 19-24.

Purwanto, 2002. Psikologi Pendidikan. Remadja Karya, Bandung.

Rosenthal, A. S. \& Henderson, C., 2006. Teaching about circuits at the introductory level: An emphasis on potential difference. American Journal of Physics. 74(4),324-328.

Smith D. P., \& Kampen P. V., 2011. "Teaching electric circuits with multiple batteries: A qualitative approach," Phys. Rev. ST Phys. Educ. Res. 7, $020115-$ 1020115-10.

Sukmadinata, 2005. Landasan Psikologi Proses Pendidikan. PT Rosda Karya, Bandung.

Suryo Subroto, 2002. Proses Belajar Mengajar di Sekolah. Rineka Cipta, Jakarta.

Telimoye Leesi, M., \& Obaitan N. Georgina, 2015. Effect of Mastery Learning on Senior Secondary School Students' Cognitive Learning Outcome in Quantitative Chemistry. N. Journal of Education and Practice, 6 (5), 34-38.

Wena, M., 2009. Strategi Pembelajaran Inovatif Kontemporer. Bumi Aksara, Jakarta. 